\title{
Dissolution Behavior of a Titanium Nitride Sponge in Titanium Alloy Melt
}

\author{
${ }^{1}$ Hideo Mizukami, 2Tomoyuki Kitaura and 3Yoshihisa Shirai \\ ${ }^{1}$ Steel Research Lab., Nippon Steel Corporation, 2-12-1, Minato, Joetsu, Niigata, 942-8510 \\ Japan \\ ${ }^{2}$ Naoetsu Works, Nippon Steel Corporation, 2-12-1, Minato, Joetsu, Niigata, 942-8510 Japan \\ ${ }^{3}$ Steel Research Lab., Nippon Steel Corporation, 20-1, Shintomi, Futtu, Chiba, 293-8511 Japan
}

Keywords : Titanium, Sponge, Nitride, Inclusion, Dissolution

\begin{abstract}
$\underline{\text { Abstract }}$
The dissolution behaviors of titanium nitride titanium sponges in titanium alloy melt were examined. A titanium nitride sponge was produced using nitrogen gas. The titanium nitride sponge featured a porous structure. Porous structures at both the surface layer and inside were formed at intervals of about $5.0 \times 10-5$ $\mathrm{m}$. When the titanium nitride sponge was immersed into a titanium alloy melt, the melt permeated into the pores. The dissolution rate of the titanium nitride sponge in the titanium alloy melt depends on the temperature of the melt. Higher melt temperatures corresponded to higher dissolution rates. However, the concentration of nitrogen in the titanium nitride sponge had no influence on the dissolution rate. Dissolution model of the titanium nitride sponge into the titanium alloy melt were proposed. These models considered the structure of the sponge; thus, the behavior of the dissolution sponges was predicted and confirmed.
\end{abstract}

\section{Introduction}

The demand for high-quality titanium alloy ingots for the aerospace industry is growing. Therefore, it is important to remove the inclusions from the melt before casting.

There are two kinds of inclusions in titanium alloys: high-density and low-density inclusions. High-density inclusions are bits of tools and machine components, which contaminate the raw material before the ingots are cast; therefore, such inclusions can be avoided in an environment with controlled conditions for handling raw materials. However, contamination due to low-density inclusions is more difficult because they are caused by a reaction, which originates in the raw materials. To prevent contamination due to with lowdensity in the ingot, these inclusions need to be dissolved in the titanium alloy melt before casting. Therefore, many studies [1-9] on the dissolution rate of low-density inclusions in titanium alloy melt have been conducted. It is necessary to understand the dissolution behaviors of the titanium sponge. However, systematic experimental studies for this phenomenon have not yet been conducted.

Titanium nitride sponges with different nitrogen concentrations were prepared from titanium sponges as the raw material. The dissolution behavior of the titanium nitride sponge in the titanium alloy melt was examined using a small electron beam furnace.

\section{Experimental Procedure}

Figure 1 shows a schematic diagram of the experimental apparatus with the small electron beam furnace.[10] The titanium alloy ingot, which was cast previously, was set in a water-cooled copper crucible in a vacuum vessel. This ingot had an upper diameter of $1.8 \times 10-1 \mathrm{~m}$, lower diameter of $1.2 \times 10-1 \mathrm{~m}$, and height of 9.0 $\times 10-2 \mathrm{~m}$, and its composition was Ti-6.4 mass $\%$ Al-4.2 mass $\%$ V. The power of the electron beam was set to $30 \mathrm{~kW}$ and the current was varied from $0.8 \mathrm{~A}$ to $1.0 \mathrm{~A}$. A molten pool was formed in the upper part of the ingot by irradiating its top surface with an electron beam. After about $1 \mathrm{~h}$, the temperature of the melt was adjusted to the prescribed temperature. The titanium nitride sponge, 


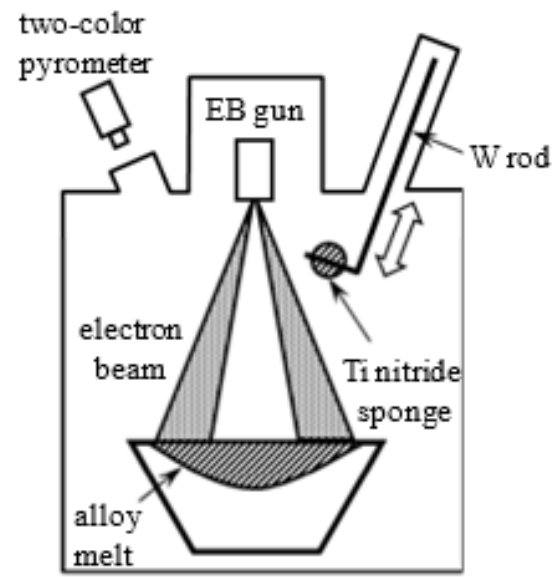

Figure 1 Schematic diagram of electron beam funnace for dissolution of titanimm nitrile sponge in titanium allow melt.

which was located above the melt, was immersed into the melt about $1.5 \times 10-2 \mathrm{~m}$ below the surface melt. At this position, the titanium nitride sponge was completely immersed. After 20 to $120 \mathrm{~s}$, the titanium nitride sponge was removed out of the melt. In this study, the titanium nitride sponge, with sizes in the range of 1.1 $\times 10-2 \mathrm{~m}$ to $1.3 \times 10-2 \mathrm{~m}$, as determined by sieving, was used. The concentration of the titanium nitride sponge was chosen in the range of 5 to 15 mass $\%$ by heat treatment with the mixed gas. A hole of $3.5 \times 10-3$ $\mathrm{m}$ in diameter was made at the center of this titanium nitride sponge, and then a tungsten rod of $3.0 \times 10-3 \mathrm{~m}$ in diameter, with an L-type-shaped front edge, was inserted in this hole.

The temperature of the alloy melt was measured with a two-color pyrometer from outside the vacuum vessel through the window.

\section{Results and Discussion}

Figure 2(a) shows the shape of the titanium nitride sponge. Figure 2(b) is the secondary electron image of the surface of the sponge and Fig. 2(c) is the optical microscope image in the center region of the sponge. It was found that the titanium nitride sponge formed as a porous structure with an interval of about $5.0 \times 10-5 \mathrm{~m}$, in addition to that observed for the titanium sponge.

Figure 3 shows the photograph of the cross section of the titanium nitride sponge that was

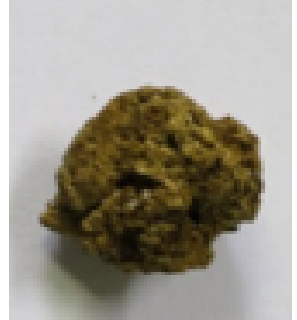

(a)

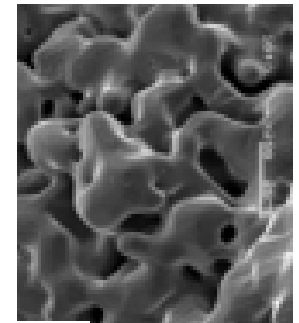

(b)

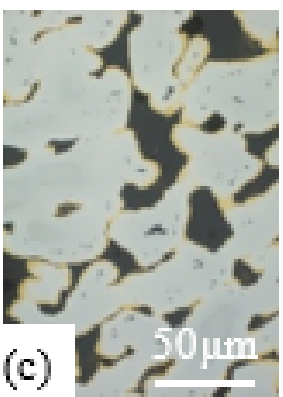

Figure 2 (a) Extemal view, (b) surface and (c) center of titanimm sponge before nitriding, respectively. 


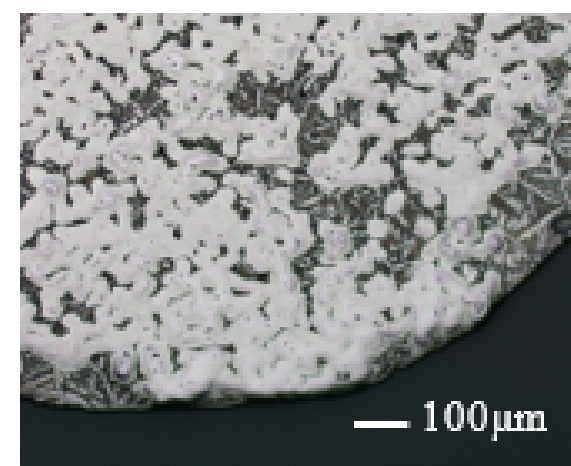

\section{Figure 3 Titanimm nitride sponge after immersion into titanium alloy melt.}

immersed into the melt, held for $70 \mathrm{~s}$, and pulled out to be inspected with an optical microscope. It was found that the alloy melt filled the pores of the titanium nitride sponge at the center in addition to the surface. Therefore, it is necessary to prepare a dissolution model of the titanium nitride sponge, which has a porous structure.

As a titanium nitride sponge is porous, it is important to evaluate the porosity of a titanium nitride sponge. Then, the porosity of a titanium nitride sponge was measured by X-ray. It was found that the opened porosity was $38.2 \%$, the closed porosity was $0.1 \%$, and then the total porosity was $38.3 \%$ for a titanium nitride sponge. It is confirmed that the pores in a titanium nitride sponge can be immersed by molten metal.

The density of a titanium nitride sponge changes depending on presence or absence of molten metal in pores. Then, the density of a compact titanium nitride was measured by Archimedes method at room temperature.

Figure 4 shows the relationship between the density of a compact titanium nitride and concentration of nitrogen. The density increased with increasing concentration of nitrogen. To obtain the density at the liquidus temperature of titanium alloy melt, the density of the room temperature was converted by using the line expansion coefficient.[11] Moreover, the density of a titanium nitride sponge can be calculated based on the density of compact titanium nitride and the porosity of titanium nitride sponge.

Figure 5 shows the relationship between the density and concentration of nitrogen when the titanium nitride sponge fills with titanium alloy melt in pores and does not fill. When the alloy melt filled the pores of the titanium nitride sponge, the density of the sponge increased and exceeded the density of titanium alloy melt. 


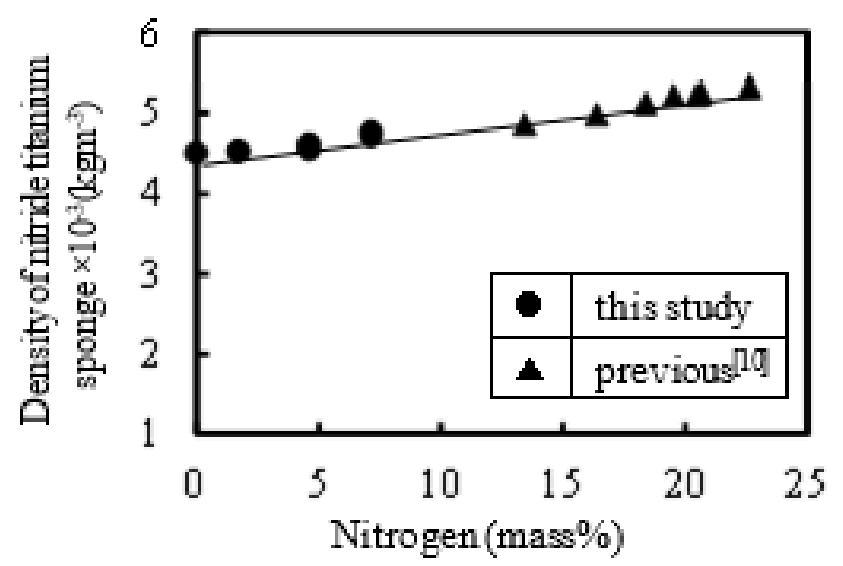

Figure 4 The relationship between the density of compact tiknimm nitride and concentration of nitrogen atroom temperature.

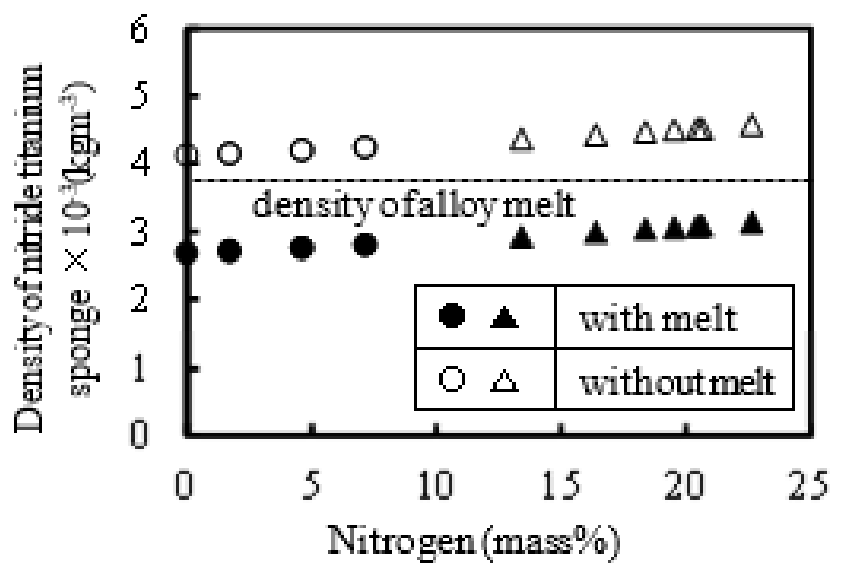

Figure 5 Change in the density of titanimm nitride sponge wilh concentration of nitrogen at liquilus temperature of titanimm albymelt.

Figure 6 shows the relationship between the dissolution rate obtained by the experiment and the reciprocal temperature when the concentration of nitrogen was $5,8,10$, and 15 mass $\%$. When the temperature of the alloy melt was high, the dissolution rate was high in all cases. However, the experimental values deviated slightly; thus, the influence of the concentration of nitrogen on the dissolution rate was not observed. It is thought that the influence of the concentration of nitrogen was not evident because the dissolution rate of the titanium nitride sponge, which was formed with a porous structure of about $5.0 \times 10-5 \mathrm{~m}$ in thickness of porous part, was high as a result of the permeation of the alloy melt into the porous structure.

To predict the dissolution rate of the titanium nitride sponge, a simple dissolution model was prepared, and the validity of the predicted values was examined by comparing them with the experimental results. 


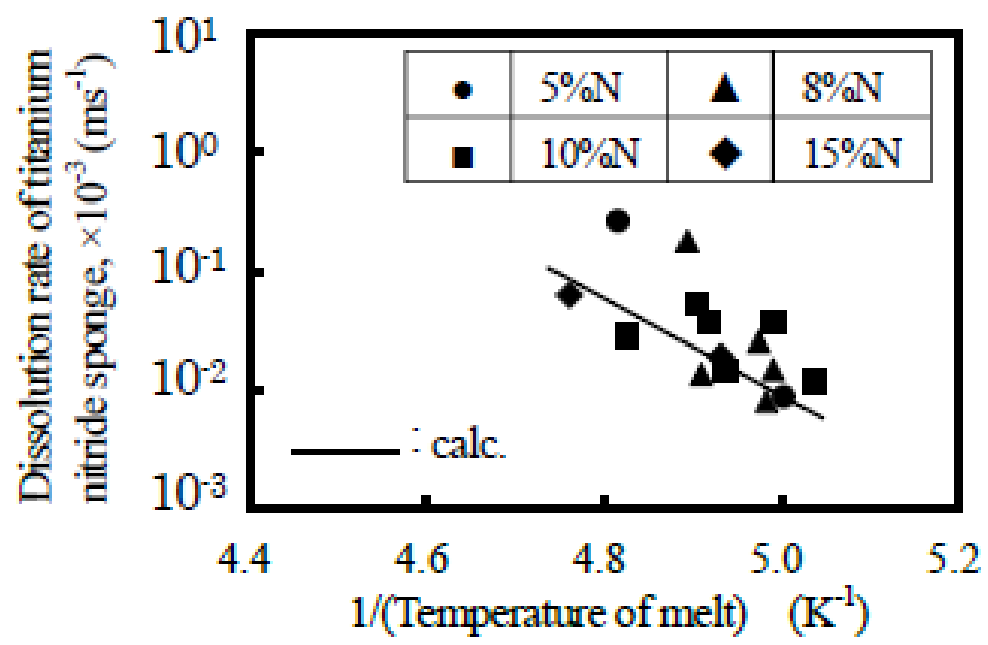

\section{Figure 6 Change in dissolution rate of titanium nitride sponges with temperature of titanium alloy melt.}

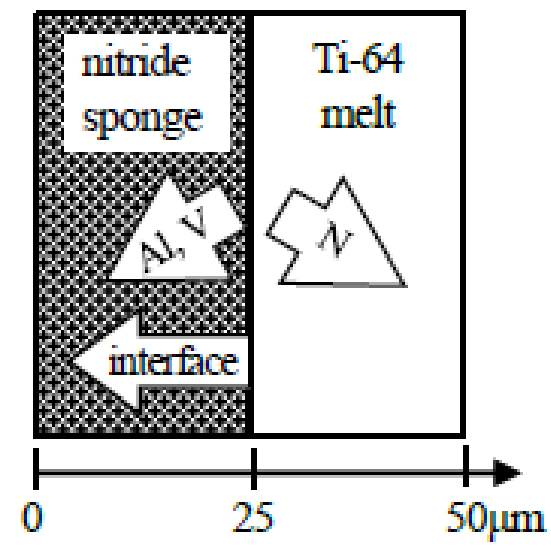

\section{Figure 7 Analytical model for dissolution of titanium nitride sponge immersed in titanium alloy melt.}

A structural model was assumed in which the solid phase of the titanium nitride was staggered in the alloy melt as liquid at $5.0 \times 10-5 \mathrm{~m}$ intervals, as shown in Fig. 7. The nitrogen diffused from the titanium nitride sponge as a solid to the alloy melt as a liquid. Conversely, aluminum and vanadium both diffused from the melt to the sponge. The relationship between the calculated dissolution rate of the titanium nitride sponge and temperature is also shown in Fig. 6. It was confirmed that the dissolution

rate of the titanium nitride sponge could be predicted by using this analytical model because the calculated value was in the range of experimental results.

\section{Conclusions}

The demand for high-quality titanium alloy ingots for the aerospace industry is growing. Therefore, it is important to remove the inclusions from the melt before casting. However, it is difficult to prevent the contamination by nitrides, because it involves the generation of a reaction product in the raw material. Therefore, it is necessary to dissolve the nitride in the alloy melt before casting.

In this study, the dissolution behavior of a titanium nitride sponge as the raw material was examined systematically. From these results, the following conclusions were obtained.

(1) The titanium nitride sponge were formed with a porous structures. The porosity interval was about $5.0 \times$ 10-5 $\mathrm{m}$ at both the surface and center of the sponge. When the nitride sponge was immersed in the titanium 
alloy melt, this melt permeated into the pores of the sponge.

(2) The dissolution rate of the titanium nitride sponge in the titanium alloy melt changed with the temperature of the melt. The dissolution rate of the sponge increased with increasing temperature. The influence of the concentration of the titanium nitride sponge on the dissolution rate was small.

(3) An analytical model for the dissolution of the titanium nitride sponge in the titanium alloy melt was constructed. By using this models, the dissolution behaviors of the sponge could be predicted.

\section{References}

[1] R.Reddy : Pro. of Electron Beam Melting and Refining State of Art, Bakish Mater., Englewood,NJ, (1990), 119.

[2] W.Buttrill and C.Shamblen : Pro. of Titanium'95, Birmingham, UK,(1995),1446.

[3] J.Bellot, S.Hans, E.Hess, C.Edie, B.Foster and A.Mitchell : Pro. of Titanium'95, Birmingham, UK, (1995), 1454.

[4] J.Bellot, B.Foster, S.Hans, E.Hess, D.Ablitzer and A.Mitchell : Metall.Mater.Trans.B, 28B(1997),1001.

[5] A.James, V.Avyle, J.Brooks and A.Powell : JOM, 50(1998),22.

[6] G.Ghazal, A.Jardy, P.Chapelle and Y.Millet : Metall.Mater.Trans.B, 41B(2010),646.

[7] G.Ghazal, P.Chapelle, A.Jardy, J.Jourdan and Y.Millet : ISIJ Int., 52(2012),1.

[8] J.Bellot, B.Detay, J.Jourdan, P.Chapelle and A.Jardy : J. Mater. Eng. Perform. : 21(2012),2140.

[9] Y.Morikawa, O.Matsuwaka and S.Ishida : CAMP-ISIJ, 29(2016),874.

[10] H.Mizukami, T.Kitaura and Y.Shirai : ISIJ Int., 59(2019), 104.

[11] K.Aigner, W.Lengauer, D.Rafaja and P.Ettmayer : J. Alloys Compounds, 215(1994), 121. 